of the blood volume is obtained without risk of such adverse reactions as intravascular coagulation.

The study by Lai et al. is a controlled trial comparing DUF with a single large-volume paracentesis for the treatment of 12 cirrhotic patients with massive ascites. The results show that the average duration of treatment was $3.26 \pm 1.49 \mathrm{hr}$ for DUF vs. $4.99 \pm 1.45 \mathrm{hr}$ for paracentesis and that the incidence of complications within 2 wk after treatment was significantly higher in patients treated with paracentesis. In fact, $50 \%$ of the patients treated with paracentesis suffered severe complications (e.g., coma, kidney failure, variceal bleeding), whereas patients treated with DUF had no complications. Therefore the authors concluded that DUF of ascitic fluid is preferable to paracentesis because it takes less time and is free of adverse effects.

Interpretation of the results of this paper requires careful observation. The number of subjects studied by Lai et al. was very small for a therapeutic trial conducted on patients with an already high spontaneous risk of complications. Moreover, large-volume paracentesis was performed at a very slow flow rate $(1 \mathrm{~L} / \mathrm{hr})$ and was not associated with any kind of plasma reexpansion, in accord with a previous study by Kao et al. (6). This method of performing therapeutic paracentesis can be, in our opinion, criticized. Several trials in which large populations of cirrhotic patients were studied demonstrated that paracentesis can be performed without any risk, with a fluid rate of tap as high as 6 to $8 \mathrm{~L} / \mathrm{hr}$, and that complications are less frequent and almost always self-limited if paracentesis is combined with adequate plasma expansion obtained with human serum albumin or with synthetic colloids (7-11). On the contrary, it is well known that large-volume paracentesis performed without plasma expansion is associated with a high rate of hypovolemia-related adverse effects $(11,12)$. Therefore it is likely that the patients in this trial could have been treated in a shorter period of time and with substantially fewer and less severe side effects if paracentesis had been conducted in accord with the methodological procedures of other authors $(9,10)$. Nevertheless, to have a method for treating refractory ascites that is completely free of any adverse effects is attractive to most clinicians. It would be worthwhile to compare DUF with other treatments of refractory ascites performed using the best methods reported in the literature in a larger population.

SALVATORE BADALAMENTI, M.D., PHD.
Divisione di Nefrologia
IRCCS Ospedale Maggiore
20122 Milan, Italy
FRANCESCO SALERNO, M.D.
Istituto di Medicina Interna
Università degli Studi
20122 Milan, Italy

REFERENCES

1. Epstein M. Treatment of refractory ascites. N Engl J Med 1989;321:1675-1677.
2. Lai KN, Leung JWC, Vallance-Owen J. Dialytic ultrafiltration by hemofilter in treatment of patients with refractory ascites and renal insufficiency. Am J Gastroenterol 1987;82:665-668.

3. Lai KM, Leung JWC, Loke J, Panesar NS, Swaminathan R, Vallance-Owen J. Ultrafiltration by hemofilter: a new therapeutic measure in intractable ascites. Int $J$ Artif Organs 1987;10: 109-114.

4. Parbhoo ST, Ajduiewicz A, Sherlock S. Treatment of ascites by continuous ultrafiltration and reinfusion of protein concentrate. Lancet 1974;1:949-952

5. Hariprasad MK, Timins JE, Eisinger RP, et al. Backflow of albumin from ascites to blood [Abstract]. Dialysis Transplantation 1981;10:608.

6. Kao HW, Rakov NE, Savage E, Reynolds TB. The effect of large-volume paracentesis on plasma volume: a cause of hypovolemia? HePATOLOGY 1985;5:403-407.

7. Salerno F, Badalamenti S, Incerti P, et al. Repeated paracentesis and iv albumin infusion to treat "tense" ascites in cirrhotic patients: a safe alternative therapy. J Hepatol 1987;5:102-108.

8. Ginès $P$, Arroyo V, Quintero E, et al. Comparison of paracentesis and diuretics in the treatment of cirrhotics with tense ascites. Gastroenterology 1987;93:234-241.

9. Ginès $\mathrm{P}$, Titò $\mathrm{L}$, Arroyo V, et al. Randomized comparative study of therapeutic paracentesis with and without intravenous albumin in cirrhosis. Gastroenterology 1988;94:1493-1502.

10. Titò $L$, Ginès $P$, Arroyo $V$, et al. Total paracentesis associated with intravenous albumin in the management of patients with cirrhosis and ascites. Gastroenterology 1990;98:146-151.

11. Salerno F, Badalamenti S, Lorenzano E, Moser P, Incerti P. Randomized comparative study of hemaccel vs. albumin infusion after total paracentesis in cirrhotic patients with refractory ascites. HEPATOLOGY 1991;13:707-713.

12. Planas $R$, Ginès $P$, Arroyo V, et al. Dextran- 70 versus albumin as plasma expanders in cirrhotic patients with tense ascites treated with total paracentesis. Gastroenterology 1990;99:662-667.

13. Panos MZ, Moore K, Vlavianos P, Chambers JB, Anderson JV, Gimson AES, Slater JDH, et al. Single, total paracentesis for tense ascites: sequential hemodynamic changes and right atrial size. HEPATOLOGY 1990;11:662-667.

\section{PULMONARY DYSFUNCTION IN ADVANCED LIVER DISEASE}

Hourani JM, Bellamy PE, Tashkin DP, Batra $P$, Simmons MS. Pulmonary dysfunction in advanced liver disease: frequent occurrence of an abnormal diffusing capacity. Am J Med 1991;90:693-700.

\section{ABSTRACT}

PURPOSE: Abnormalities in pulmonary function have been reported in association with chronic liver disease of varied etiology. The aim of this study was to better define the frequency and nature of these abnormalities in patients who were being evaluated for liver transplantation.

PATIENTS AND METHODS: We performed a battery of pulmonary function tests and chest radiographs in 116 consecutive patients ( 50 men, 66 women; aged 19 to 70 years, mean 44.6 years) with severe advanced liver disease who were hospitalized specifically for evaluation for possible orthotopic liver transplantation and were able to perform technically satisfactory tests. In 17 patients, quantitative whole-body technetium-99m macroaggregated albumin perfusion scanning was also performed for assessment of possible right-to-left shunting through intrapulmonary vascular dilatations. 
RESULTS: The most commonly affected test of lung function was the single-breath diffusing capacity for carbon monoxide ( $\left(\mathrm{L}_{\mathrm{co}}\right)$, which was abnormal in $48 \%$, $45 \%$, and $71 \%$ of patients who never smoked, former smokers, and current smokers, respectively. Ventilatory restriction was noted in $25 \%$ of all patients, airflow obstruction (reduced ratio of forced expiratory volume in 1 second to forced vital capacity) in only $3 \%$, and a widened alveolar-arterial oxygen gradient in 45\%. Diffusion impairment was accompanied by a restrictive defect in only $35 \%$ of the patients and by an abnormally widened alveolar-arterial oxygen gradient in $60 \%$. When diffusion impairment was accompanied by an oxygenation defect, it was also associated with a significantly increased right-to-left shunt fraction (mean $24.9 \%$ ) assessed from quantitative whole-body perfusion imaging. On the other hand, isolated diffusion impairment unaccompanied by significant hypoxemia (noted in approximately a third of the patients with a reduced $D L_{c o}$ ) was not associated with evidence of significant intrapulmonary shunting (mean rightto-left shunt fraction $6.7 \%$ ).

CONCLUSIONS: Most patients with advanced liver disease have one or more types of abnormality in lung function, a reduced $\mathrm{DL}_{\mathrm{co}}$ being the single most common functional defect. Mechanisms accounting for the abnormality in gas transfer may include intrapulmonary vascular dilatations, diffuse interstitial lung disease, pulmonary vaso-occlusive disease, and/or ventilationperfusion imbalance.

\section{COMMENTS}

Since 1884, liver disease has been known to be associated with pulmonary abnormalities (1). Many studies have reported that patients with severe liver disease usually have mild hypoxemia and abnormal diffusing capacity. Most of the literature on the subject is of limited value in that the number of subjects is usually small; the degree of liver disease is different from study to study, making comparisons difficult; and the results of pulmonary function testing and diffusing capacity (DLCO) are not available on all subjects. Although many mechanisms have been proposed, the cause or causes of pulmonary dysfunction in these patients remain unclear.

One of the earlier proposed mechanisms for hypoxemia in patients with liver disease was decreased 2,3DPG leading to abnormal oxygen dissociation curve (2). This has been proven not to be true and has fallen out of favor. Several studies have shown that a rightto-left shunt secondary to "pulmonary spider angioma" may be an important cause of abnormal DLCO and hypoxemia, especially in patients with peripheral spider angioma $(3,4)$. Dilated pulmonary vessels are predominantly found in lower lobes. When a person assumes an upright position an increase is seen in blood flow to the lower lobes secondary to gravity. This causes more shunting and worsening hypoxemia (i.e., orthodeoxia). However, pulmonary spider angioma are not present in all patients with pulmonary abnormalities. Another common cause of hypoxemia in patients with liver disease is ventilation/perfusion mismatch, which can be caused by atelectasis, pulmonary edema, pleural effusion or an elevated diaphragm secondary to ascites or massive hepatomegaly. One of the factors that causes abnormal ventilation/perfusion is an increased closing capacity. Normally closing volume is smaller than functional residual capacity such that airways remain open at the end of normal exhalation. Some studies demonstrated that patients with liver disease have larger closing volume leading to earlier closure of airways ( 5 , 6). Other studies, however, found no change in closing capacity in patients with liver disease when compared with controls (7).

The paper reviewed here studied 116 subjects who were being evaluated for liver transplantation. It is interesting that only $52(45 \%)$ had an elevated $\mathrm{A}-\mathrm{a} \mathrm{O}_{2}$ gradient despite the fact that all these patients had severe liver disease. Although abnormal DLCO was the most common functional defect in these patients, it was present in only $60(52 \%)$ of 116 patients. An elevated A-a $\mathrm{O}_{2}$ gradient and abnormal DLCO was concomitantly present in 36 patients. Twenty-nine patients had a restrictive ventilatory defect (total lung capacity less than $80 \%$ of predicted). Not surprisingly, most of these patients had radiographic evidence of decreased lung volumes, ascites and/or pleural effusion and elevated A-a $\mathrm{O}_{2}$ gradient and abnormal DLCO. Fourteen patients had an abnormal DLCO with a normal A-a $\mathrm{O}_{2}$ gradient. It is recognized that DLCO is the more sensitive measurement of pulmonary dysfunction than either lung volumes or hypoxemia. It is probable that abnormal diffusion capacity in these patients reflects an early change in pulmonary physiological processes. Of the 17 patients who had whole-body technetium-99m macroaggregated albumin perfusion scanning, only 6 had significantly elevated right-to-left shunting. All of these patients had concomitant hypoxemia and diffusion impairment. This is in agreement with other studies (8, 9 ). Increased shunting is most likely caused by the presence of dilated pulmonary capillaries. It is unknown what factors in patients with severe liver disease cause the dilatation.

This study reflects the difficulties inherent in examining pulmonary dysfunction in cirrhotic patients, namely, different degrees of liver disease and multiple factors leading to hypoxemia in these patients. Although anecdotal cases exist of patients whose pulmonary dysfunction resolved with the improvement of liver disease, liver transplantation or both, it is not known whether all of processes leading to pulmonary dysfunction are reversible with liver transplantation. It would have been interesting to know whether any changes in pulmonary dysfunction were seen after liver transplantation in these patients.

SUCHA KIM, M.D.
Division of Pulmonary and
Critical Care Medicine
Department of Internal Medicine
University of Michigan Medical Center
Ann Arbor, Michigan 48109

SUCHA KIM, M.D.

Department of Internal Medicine

Ann Arbor, Michigan 48109 


\section{REFERENCES}

1. Fluckiger M. Vorkommen von trommelschlagel ormigen Fingerendphalangen ohne chronische Veranderungen an den Lunger oder am Herzen. Wien Med Wochenschr 1884;34:1457.

2. Keys A, Snell AM. Respiratory properties of arterial blood in normal man and in patients with disease of liver: position of oxygen dissociation curve. J Clin Invest 1938;17:59-67.

3. Berthelot P, Walker JG, Sherlock S, Reid L. Arterial changes in the lungs in cirrhosis of the liver-lung spider nevi. N Engl J Med 1966;274:291-298.

4. Krowka MJ. Hepatopulmonary syndrome: an evolving perspective in the era of liver transplantation. HEPATOLOGY 1990;11:138-142.

5. Ruff F, Hughes MB, Stanley D, et al. Regional lung function in patients with hepatic cirrhosis. J Clin Invest 1971;50:2403-2413.

6. Furukawa T, Nobuyuke H, Yasumoto K, Inokuchi K. Arterial hypoxemia in patients with hepatic cirrhosis. Am J Med Sei 1984;287:10-13.

7. Funahashi A, Kutty AVP, Prater SL. Hypoxaemia and cirrhosis of the liver. Thorax 1976;31:303-308.

8. Wolfe JD, Tashkin DP, Holly FE, et al. Hypoxemia of cirrhosis: detection of abnormal small pulmonary vascular channels by a quantitative radionuclide method. Am J Med 1977;63:746-754.

9. Stanley NN, Ackrill P, Wood J. Lung perfusion scanning in hepatic cirrhosis. BMJ 1972;4:639-643.

\section{Reviews Elsewhere}

Schmitz G, Müller G. Structure and function of lamellar bodies, lipid-protein complexes involved in storage and secretion of cellular lipids. J Lipid Res 1991;32:1539-1570.

Overview of the function of lamellar bodies, lipid storage and secretory organelles. The function of lamellar bodies in various organs including bile is discussed.

Eisensmith RC, Woo SLC. Phenylketonuria and the phenylalanine hydroxylase gene. Mol Biol Med 1991;8:3-18.

Review article that discusses the diseases associated with defects in the phenylalamine hydroxylase (PAH) gene. $\mathrm{PAH}$ is a mixed-function oxygenase that mediates the parahydroxylation of L-phenylalanine to L-tyrosine. In human beings, this enzyme appears to be expressed exclusively in the liver.

Schaerer E, Neutra MR, Kraehenbuhl J-P. Molecular and cellular mechanisms involved in transepithelial transport. J Memb Biol 1991;123: 93-103.

This review discusses transcellular transport or transcytosis, a vesicular transport across polarized all-cell layers of epithelia and endothelia. It is proposed that transcytosis plays a dual role in epithelial cells. It maintains cell polarity and also serves as vectorial delivery of substances.

\section{Elsewhere Correspondence}

\section{LOWER RATES OF POSTBIOPSY BLEEDING: NEEDLE VS. TECHNIQUE}

To the Editor:

I read with interest Dr. Harold Conn's review (1) of the article by McGill et al. (2) that reported the Mayo
Clinic experience with hemorrhage after percutaneous liver biopsy using Tru-Cut and Jamshidi needles. In his review, Doctor Conn compares the Mayo group's results with an Italian group's experience with hemorrhage after percutaneous liver biopsy performed almost exclusively with the Menghini needle (3). Conn points out that the $0.04 \%$ incidence of hemorrhage in the Italian experience is significantly lower than the $0.4 \%$ incidence in the Mayo study $(p<0.0001)$. He also notes that the incidence of fatal hemorrhage was also significantly lower in the Italian group as compared with the Mayo group ( $p<0.001)$. However, the percentage of patients in the Italian study with fatal hemorrhage is not $0.05 \%$ as reported by Conn but $0.005 \%$ ( 3 of 60,611 ). This corresponds to an even more significant decreased incidence of fatal hemorrhage in the Italian group compared with the Mayo experience $(p<0.0001)$. The corrected statistics give further support to the safety of the Menghini needle used by the Italian group compared with the Jamshidi and Tru-Cut needles used by the Mayo group.

\section{ALAN M. SCHULLER, M.D. Division of Gastroenterology Long Island College Hospital SUNY Health Science Center at Brooklyn Brooklyn, New York 11201}

\section{REFERENCES}

1. Conn HO. Liver biopsy: increased risks in patients with cancer. HEPATOLOGY 1991;14:206-209.

2. McGill DB, Rakela J, Zinsmeister AR, Ott BJ. A 21-year experience with major hemorrhage after percutaneous liver biopsy. Gastroenterology 1990;89:1396-1400.

3. Piccinino F, Sagnelli E, Pasquale G, Giusti G. Complications following percutaneous liver biopsy: a multicentre retrospective study on 68,276 biopsies. J Hepatol 1986;2:165-173.

\section{Reply:}

The mathematical error noted by Dr. Schuller in my essay is indeed an error. Fatal hemorrhages occurred with the Menghini needle in $0.005 \%$, not $0.05 \%$ as I had indicated. As he notes, this makes the risks of postbiopsy bleeding even smaller with the Menghini needle used by the Italian group than with the Jamshidi needle used by the Mayo group ( $\mathrm{p}<0.0001)$.

This difference, however, cannot be attributed solely to differences in the needles themselves. Differences in the techniques used by the two groups and differences in the types of patients studied almost certainly contributed to the higher incidences of both postbiopsy bleeding and fatal postbiopsy hemorrhage in the Mayo series. These differences include the following: (a) a higher prevalence of neoplasia in the Mayo patients; (b) the biopsy protocol used by the Mayo physicians in patients suspected of having malignancy in whom multiple passes were performed - as many as 11 - until neoplastic tissue was obtained; (c) the older age of the Mayo patients; (d) the greater prevalence of cancer in the 